\title{
In vivo bioactivity of DNA-based coatings: An experimental study in rats
}

\author{
Corinne Schouten, ${ }^{1}$ Jeroen J. J. P. van den Beucken, ${ }^{1}$ Gert J. Meijer, ${ }^{1}$ Nico A. J. M. Sommerdijk, ${ }^{2}$ \\ Paul H. M. Spauwen, John A. Jansen ${ }^{1}$ \\ ${ }^{1}$ Department of Periodontology and Biomaterials, Radboud University Nijmegen Medical Center, Nijmegen, \\ The Netherlands \\ ${ }^{2}$ Laboratory for Macromolecular and Organic Chemistry, Eindhoven University of Technology, Eindhoven, \\ The Netherlands \\ ${ }^{3}$ Department of Plastic and Reconstructive Surgery, Radboud University Nijmegen Medical Center, Nijmegen, \\ The Netherlands
}

Received 27 June 2008; revised 7 November 2008; accepted 11 November 2008

Published online 16 March 2009 in Wiley InterScience (www.interscience.wiley.com). DOI: 10.1002/jbm.a.32446

\begin{abstract}
DNA-based coatings possess beneficial properties useful for medical and dental implants. The present study evaluated the potential in vivo bioactivity of DNAbased coatings, either or not pretreated in simulated body fluid (SBF). DNA-based coatings were generated on titanium cylinders using layer-by-layer deposition, with bisureido-surfactant as the cationic component and DNA as the anionic component. Noncoated titanium implants and CaP-coated implants served as controls. A total of 80 implants, divided in four experimental groups $(n=10)$ were implanted unilaterally into the lateral femoral condyles of 80 rats. After implantation periods of 1 and 4 weeks, the bone-to-implant contact and bone volume around the implants were determined histomorphometrically. The results of this study showed that DNA-based coatings and
\end{abstract}

CaP coatings increased bone-to-implant contact after 1 week compared to noncoated controls. After 4 weeks of implantation, bone-to-implant contact increased significantly for SBF pretreated DNA coatings and CaP coatings, whereas DNAcoated implants showed no additional effect. The bone-toimplant contact of noncoated controls increased to the level of the DNA-coated implants. Consequently, this study demonstrates that DNA-based coatings are histocompatible and favor early bone responses. SBF-pretreated DNA-based coatings were found to increase both early and late periimplant bone responses. (c) 2009 Wiley Periodicals, Inc. J Biomed Mater Res 92A: 931-941, 2010

Key words: DNA-coating; layer-by-layer deposition; bioactivity; SBF; (animal) rat study

\section{INTRODUCTION}

In the field of implantology, a wide variety of materials are used to generate biomedical devices with satisfactory properties to replace body parts that have been damaged or lost. Many types of metals (or metallic alloys), ceramics, and polymers, or combinations thereof, have been used for the construction of medical and dental implants. ${ }^{1}$ Commercially pure titanium (Ti) is one of the most widely used materials for manufacturing load-bearing implants. The use of titanium for bone implants is based on the combination of mechanical properties and corrosion resistance. ${ }^{2}$

Correspondence to: J. A. Jansen; e-mail: j.jansen@dent. umcn.nl

Contract grant sponsor: Dutch Program for Tissue Engineering (DPTE); contract grant number: NGT.6730

(C) 2009 Wiley Periodicals, Inc.
However, as metals usually do not show bioactive behavior, that is, they do not form a direct bond between the implant and the surrounding bone tissue, methods have been sought to improve the biological contact at the implant/tissue interface. Consequently, bioactive materials, such as calcium phosphate (CaP) ceramics, have been routinely applied as thin coatings onto metallic substrates to combine the mechanical properties of the metal with the excellent biological properties of CaP ceramics. ${ }^{3,4}$

Various deposition techniques have been used to apply CaP coatings onto implants, of which plasmaspraying and magnetron sputtering are the most widely used. Although the osteoconductive and bioactive properties of $\mathrm{CaP}$ coatings derived with these techniques have been confirmed by numerous studies, 5,6 these coating methods still have important limitations. For instance, both techniques are associated with extremely high temperatures for post-treatment of the coatings to transform the as-deposited amor- 
phous coatings into a crystalline phase. This makes the incorporation of biologically active compounds (e.g. growth factors) impossible. In addition, inherent to both line-of-sight techniques is that only simple (nonporous) 2D objects can be provided with a $\mathrm{CaP}$ coating. In the field of regenerative medicine, for example, in craniofacial skeletal reconstructions, however, scaffolds must fit very complex threedimensional (3D) anatomic defects.

To overcome these limitations, studies have been undertaken to find methods to increase surface bioactivity. As proposed by Kokubo and Takadama, immersion of materials in simulated body fluids (SBF), which are solutions that are compositionally similar to human blood plasma, is a well-defined method to obtain predictive information on the materials in vivo bone-like apatite formation on the implant surface. With the use of SBF in in vitro experiments, in which in vivo apatite formation can be mimicked, it has been demonstrated that negatively charged groups, that is, phosphate-containing groups in particular, are the most potent inducers of the CaP nucleation process. ${ }^{9}$

In view of the aforementioned findings, a recently proposed implant coating with deoxyribose nucleic acid (DNA) as its main component has shown favorable $\mathrm{CaP}$ nucleation in comparison with titanium control. ${ }^{10}$ The idea behind the DNA-based coatings is that, irrespective of its genetic information, DNA has beneficial biomaterial properties, which include nonor low immunogenicity, capability to bind other biologically active compounds (e.g., proteins or antibiotics), and a high phosphate content. In view of these properties, van den Beucken et al. fabricated and characterized multilayered DNA-based coatings for biomaterial purposes, whose generation is based on the layer-by-layer (LbL) deposition technique. ${ }^{11}$ This technique has been used previously for the generation of various biomedical coatings which have been tested in rat animal models. ${ }^{12-14}$ The results of these in vivo experiments have demonstrated prolonged stability (up to 3 months) at different implantation sites. The multilayered DNA-based coatings further demonstrated to be cyto- and histocompatible, ${ }^{15}$ and eligible for functionalization with growth factors. ${ }^{16,17}$ The earlier mentioned positive effect of phosphate-containing groups on the $\mathrm{CaP}$ nucleation process, was also observed for DNA-based coatings in comparison with titanium in an SBF-soaking experiment. In addition, SBF-pretreated DNA-based coatings affected the differentiation of osteoblast-like cells through an increased deposition of osteocalcin. ${ }^{10}$ The results of this in vitro study are indicative for bone-bonding capacities of DNA-based coatings, though conclusive data on in vivo bioactivity are lacking.

In the present study, originally used cationic polyelectrolytes for the generation of DNA-based coat- ings were replaced by Bis-Ureido-Surfactant (BUS). This surfactant molecule functions by the formation of strong hydrogen bonds resulting in well-defined highly ordered ribbon-like bilayer aggregates, ${ }^{18}$ ensuring the presence of DNA at the surface.

Consequently, the present study aimed at evaluating the potential in vivo bioactivity of BUS/DNA coatings, either or not pretreated in SBF. For this purpose, BUS/DNA coatings were prepared on titanium cylinders. Noncoated titanium cylinders served as negative controls, whereas titanium cylinders with a CaP-sputter coating served as positive controls. The surfaces of all implant types were evaluated morphologically and physicochemically before initiation of the in vivo implantation study. For the in vivo experiment, the four types of implants were inserted into the lateral femoral condyle of rats for 1 and 4 weeks to determine the osteogenic response, which consisted of qualitative (histology) as well as quantitative (histomorphometry) analyses.

\section{MATERIALS AND METHODS}

\section{Materials}

Polyanionic salmon DNA $( \pm 300 \mathrm{bp} /$ molecules; sodium salt) was kindly provided by Nichiro Corporation (Kawasaki-city, Kanagawa prefecture, Japan). BUS (Bis-UreidoSurfactant) was kindly provided by Dr. Nico Sommerdijk and Dr. Matthijn Vos (Laboratory for Macromolecular and Organic Chemistry, Eindhoven University of Technology, The Netherlands).

\section{Implant preparation and cleaning}

Eighty cylindrical titanium implants (diameter: $1.75 \mathrm{~mm}$; length: $3.5 \mathrm{~mm}$; commercially-pure titanium) were used. Prior to coating deposition, implants were cleaned ultrasonically in nitric acid 10\% (15 min), acetone (15 min), and isopropanol (15 min), respectively. Subsequently, the implants were air-dried.

\section{Coating generation}

The implants were left uncoated or provided with either a multilayered DNA-coating or a CaP sputter coating.

\section{$L b L$ deposition of multilayered DNA coatings}

Multilayered DNA coatings were generated using the LbL deposition technique with BUS $^{18}$ as the cationic component and DNA as the anionic component. Briefly, the cleaned implants were immersed in an aqueous solution of BUS $(5 \mathrm{mg} / \mathrm{mL}$ ) for $30 \mathrm{~min}$, thereby allowing sufficient time for the adsorption of BUS (the first cationic polyelec- 
trolyte layer) onto the implants. Subsequently, implants were washed in ultra-pure water. Thereafter, substrates were immersed alternately in an anionic aqueous DNA solution $(1 \mathrm{mg} / \mathrm{mL})$, and a BUS solution $(1 \mathrm{mg} / \mathrm{mL})$ for $7 \mathrm{~min}$ each, with intermediate washing in ultra-pure water (5 min; continuous water flow). The build-up of the multilayered DNA-coatings was continued until a total of 5 double-layers was reached with a final coating architecture of $[\mathrm{BUS} / \mathrm{DNA}]_{5}$ (the number indicates the total number of double layers).

\section{Deposition of CaP sputter coatings}

Prior to $\mathrm{CaP}$ coating deposition, implants were gritblasted with $\mathrm{Al}_{2} \mathrm{O}_{3}\left(R_{\mathrm{a}}=0.8-1.0 \mu \mathrm{m}\right)$. Subsequently, the $\mathrm{CaP}$ coatings were deposited using a commercially available RF magnetron sputter unit (Edwards ESM 100) as described previously by Wolke et al. ${ }^{19}$ The process pressure was $5 \times 10^{-3}$ mbar and the sputter power $400 \mathrm{~W}$. Resultant coating thickness was $\sim 2.0 \mu \mathrm{m}$. After deposition, all coated implants were subjected to an additional heat treatment for $2 \mathrm{~h}$ at $550^{\circ} \mathrm{C}$ in a chamber furnace (UAF, Lenton, Hope Valley, England).

\section{SBF pretreatment of DNA-based coatings}

The recipe for the preparation of SBF was adopted from Kokubo and Takadama. ${ }^{8}$ Pre-treatment of the DNA-coated implants was performed with SBF containing a 2-fold increased calcium- and phosphate-ion concentration $\left(\mathrm{SBF}_{2}\right)$ compared to human blood plasma. Briefly, chemicals were dissolved in sequence into distilled water, one by one to prevent precipitation in the solution during preparation. After complete dissolution of the reagents, $\mathrm{pH}$-value was set at 7.4. Immersion studies were performed in $15-\mathrm{mL}$ tubes (Greiner Bio-One B.V., Alphen aan de Rijn, The Netherlands), using 1 implant per tube in $4 \mathrm{~mL} \mathrm{SBF}$. Tubes were placed in a water bath at $37^{\circ} \mathrm{C}$ under continuous shaking. The SBF solution was refreshed on a weekly basis. After an immersion period of 2 weeks, implants were thoroughly rinsed (3 times) with ultra-pure water, and air-dried.

\section{Surface morphology}

Scanning electron microscopy (SEM) was performed to examine the surface morphology of the implants. Therefore, the substrates were sputter coated with gold and examined using a Jeol 6310 scanning electron microscope at an acceleration voltage of 10-15 kV (SEM; Jeol 6310, Tokyo, Japan).

\section{Surface analysis}

The crystallographic structure of depositions on the substrates was characterized using a Philips thin film X-ray diffractometer with $\mathrm{CuK} \alpha$-radiation (XRD; PW3710, Almelo, The Netherlands). In addition, average surface roughness values $\left(R_{\mathrm{a}}\right)$ were determined using a Universal Surface Tester (UST; Innowep, Wurzburg, Germany).

\section{Experimental animal groups}

In the animal study, a total of four different experimental groups were used:

$$
\begin{aligned}
& 1 \mathrm{Ti} \text {, noncoated } \\
& 2 \mathrm{Ti}+[\mathrm{BUS} / \mathrm{DNA}]_{5} \\
& 3 \mathrm{Ti}+[\mathrm{BUS} / \mathrm{DNA}]_{5}+\mathrm{SBF} \\
& 4 \mathrm{Ti}+\mathrm{CaP}
\end{aligned}
$$

Sterility was obtained through autoclavation of noncoated and CaP-coated implants. Generation of the DNAcoating was performed under aseptic conditions after autoclavation of cleaned implants.

\section{Surgical procedure}

All in vivo work was conducted in accordance with ISO standards, and protocols of the Central Animal Facility (CDL; Radboud University Nijmegen Medical Center, Nijmegen, The Netherlands). National guidelines for the care and use of laboratory animals were observed, and approval of the Experimental Animal Ethical Committee was obtained. A total of 80 implants (10 implants per experimental group for each implantation period; $n=10$ ) were implanted unilaterally into 80 male Wistar rats (1 implant per rat), with a mean body weight of about $250 \mathrm{~g}$. Surgery was performed under general inhalation anesthesia, and sterile conditions. To reduce the postoperative pain, Rimadyl $^{\circledR}(5.0 \mathrm{mg} / \mathrm{kg})$ and Morphine ${ }^{\mathbb{R}}(1.0 \mathrm{mg} / \mathrm{kg})$ were administered subcutaneously pre-operative. Before the insertion of the implants, each animal was immobilized on its back, and the hind limbs were shaved, washed, and disinfected with povidone-iodine. For implantation of the implant in the femur, a longitudinal incision was made over the patella. By flexion of the knee joint, and shifting aside of the patellar ligament, both femoral condyles were fully exposed. After exposure of the condyles a hole with a diameter of $1.75 \mathrm{~mm}$ was drilled using a dental bur (Elcomed 100, W\&H Dentalwerk Burmoos, Austria) in the lateral femoral condyle of either the right or the left limb, according to statistic randomization. The bone defect preparation was performed with a gentle surgical technique, using low rotational drill speeds (800-1200 rpm), and continuous external cooling with saline. In this way, one hole was made on the lateral side of the condyle, resulting in one implant site per rat. After preparation, the hole was irrigated and the implant inserted (Fig. 1). After insertion of the implants, the soft tissues were closed with resorbable sutures (Vicryl ${ }^{\mathbb{R}}$ 4.0; Ethicon Products, Amersfoort, The Netherlands), and the skin with skin staples (Agraves; InstruVet, Cuijk, The Netherlands). To reduce postoperative pain, all rats received one subcutaneous injection with Temgesic ${ }^{\mathbb{R}}(20 \mu \mathrm{g} / \mathrm{kg})$ and Rimadyl ${ }^{\mathbb{R}}$ for 2 days postoperatively. After both 1 and 4 weeks postimplantation, 40 rats were euthanized by an overdose of $\mathrm{CO}_{2}$, and the implants with surrounding tissue were retrieved for histological evaluation. 


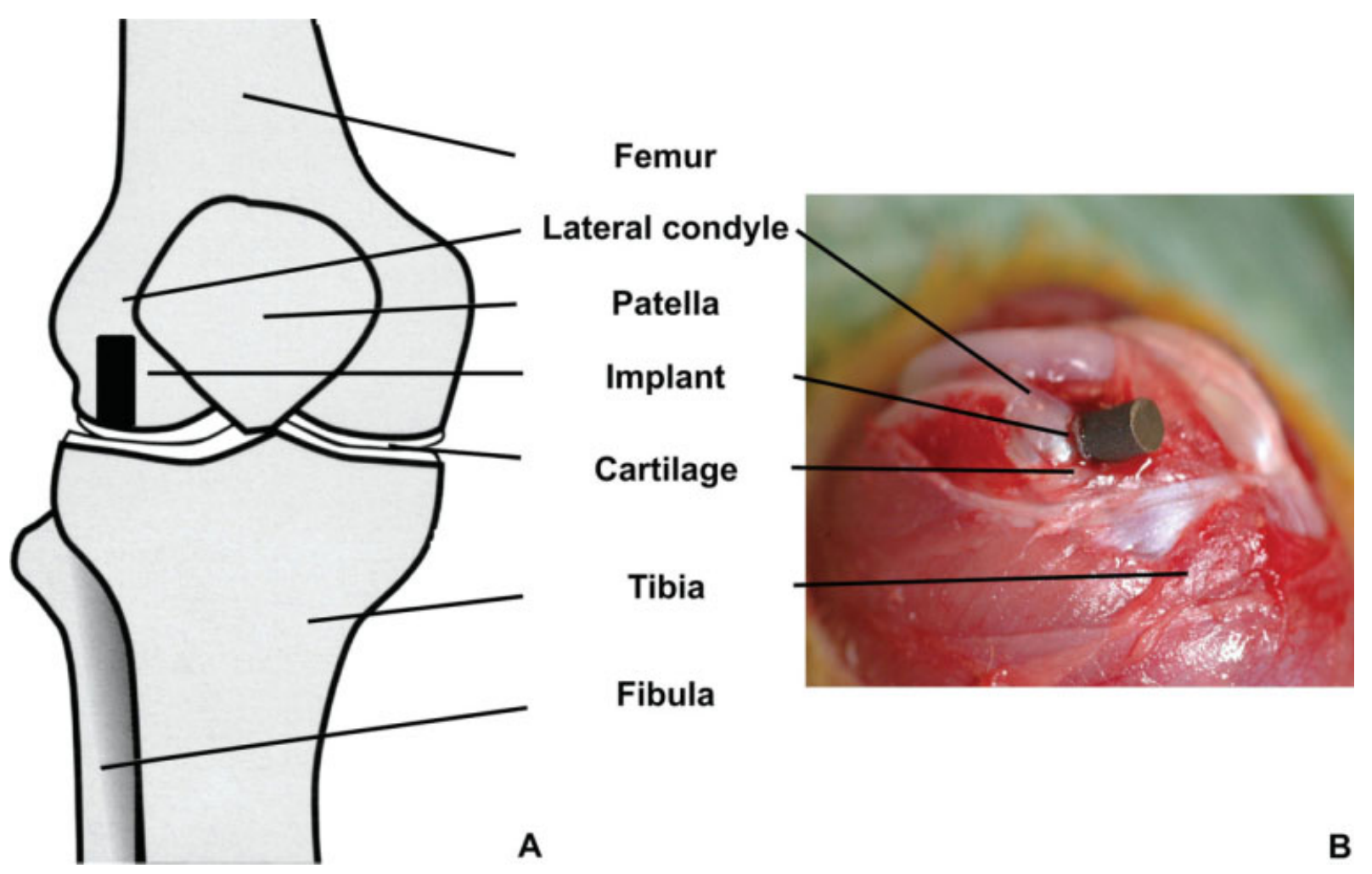

Figure 1. A (left): Location of implant site in the lateral femoral condyle. The black bar represents the implant. B (right): Titanium cylinder inserted in the lateral femoral condyle of a rat. [Color figure can be viewed in the online issue, which is available at www.interscience.wiley.com.]

\section{Histological preparations}

After the animals were sacrificed, the femoral condyles were retrieved, excess tissue was removed, and using a diamond circular saw, the condyles were divided into smaller specimens suitable for histological processing. Subsequently, the tissue blocks were fixed in $10 \%$ neutral buffered formalin solution, dehydrated in a graded series of ethanol (70-100\%), washed with acetone, and embedded in methyl methacrylate (MMA) for 4 weeks. After polymerization, nondecalcified thin sections, cross-sectional to the axis of the implants, were prepared (at least 3 of each implant), using a modified sawing microtome technique ${ }^{20}$ and stained with methylene blue and basic fuchsin.

\section{Histological and histomorphometrical evaluation}

To evaluate the trabecular bone response to the implants, histological and histomorphometrical analyses were performed. Histological evaluation using a light microscope DMRD (Leica Microsystems AG, Wetzlar, Germany) consisted of a concise description of the observed tissues reaction, including the structure and arrangement of cells, implant, and tissue-implant interface. In addition, a computer-based image analysis technique (Leica Qwin Proimage analysis software; Leica Imaging Systems, Cambridge, UK) was used for histomorphometrical evaluation. The quantitative measurement was performed for three dif- ferent sections per implant. The average of these three measurements was used for statistical analysis. The quantitative parameters assessed were bone-implant contact and bone volume (at magnification $25 \times$ ). The amount of bone contact was defined as the percentage of implant length at which there is direct bone-to-implant contact. In cross-sectional histological sections, the implant edge was selected manually after which the bone in direct contact with the implant edge was determined as a percentage of the circumference of the implant. To determine the amount of bone volume, a circle with a diameter of $2.25 \mathrm{~mm}$ (ROI) was centered over the implant. Subsequently, the implant area was measured (IA), which was subtracted from the ROI, yielding the area of interest (AOI). Thereafter, the amount of bone tissue in the AOI was selected manually and defined as the percentage of the AOI, yielding the definite amount of bone volume per implant.

\section{Statistical analysis}

Statistical analyses of the surface roughness values $\left(R_{\mathrm{a}}\right)$, bone-implant contact, and bone volume measurements were performed using GraphPad Instat, version 3.0 (GraphPad Software, San Diego, CA). Statistical comparisons for roughness, bone implant contact, and bone volume of the four different experimental groups were performed using a one-way ANOVA, combined with a post hoc Tukey-Kramer Multiple Comparisons Test. Addition- 
ally, statistical comparisons for each experimental group between the two implantation periods (week 1-week 4) were performed using an unpaired $t$-test. Data shown are means + SD. The significance level was set at a probability ( $p$ ) value smaller than 0.05 .

\section{RESULTS}

\section{Surface analysis and morphology}

The XRD analyses of the heat-treated $\left(550^{\circ} \mathrm{C}\right)$ sputter coating revealed a crystalline $\mathrm{CaP}$ coating with mean diffraction peaks of apatitic calcium phosphate at $2 \theta=25.9^{\circ}(002), 31.9^{\circ}(211), 32.4^{\circ}(112), 33.2^{\circ}$ (300), and $34.0^{\circ}$ (202). Analyses of the [BUS/DNA] $]_{5}$ + SBF substrates revealed a poorly crystalline apatitic nature with diffraction peaks at $2 \theta=25.9^{\circ}(002)$, and $31.9^{\circ}$ (211), (data not shown).

The results of the surface roughness measurements and the outcome of the statistical analyses are depicted in Table I. The surfaces of the different experimental implants had an average surface roughness value $\left(R_{\mathrm{a}}\right)$ of $0.16,0.21,0.25$, and 1.47 for noncoated controls, $[\mathrm{BUS} / \mathrm{DNA}]_{5}$, $[\mathrm{BUS} / \mathrm{DNA}]_{5}+\mathrm{SBF}$, and $\mathrm{CaP}$, respectively. In comparison with the noncoated controls, statistically significant differences were observed for $[\mathrm{BUS} / \mathrm{DNA}]_{5}+\mathrm{SBF}(p<0.05)$ and $\mathrm{CaP}(p<0.001)$. Additionally, the surface roughness of $\mathrm{CaP}$ was significantly higher compared to both $[\mathrm{BUS} / \mathrm{DNA}]_{5}$ and $[\mathrm{BUS} / \mathrm{DNA}]_{5}+\operatorname{SBF}(p<0.001)$.

Scanning electron micrographs of the different experimental implant surfaces, showed apparent differences between all experimental groups (Fig. 2). Images of the noncoated controls showed the original surface morphology of as-machined Ti. Observation of the [BUS/DNA] $]_{5}$-coated surfaces with low magnification $(750 \times)$ did not show the presence of the deposited DNA-based coating. At higher magni-

TABLE I

\section{Determination of Surface Roughness}

\begin{tabular}{ll}
\hline Experimental Surface & $R_{\mathrm{a}}(\mu \mathrm{m} \pm \mathrm{SD})$ \\
\hline Noncoated (Titanium) & $0.16 \pm 0.01$ \\
{$[\mathrm{BUS} / \mathrm{DNA}]_{5}$} & $0.21 \pm 0.02$ \\
{$[\mathrm{BUS} / \mathrm{DNA}]_{5}+\mathrm{SBF}$} & $0.25 \pm 0.01^{*}$ \\
$\mathrm{CaP}$ & $1.47 \pm 0.07^{* * *}$ \\
\hline
\end{tabular}

$R_{\mathrm{a}}$, surface roughness.

Statistical analyses were performed using a one-way ANOVA, combined with a post hoc Tukey-Kramer multiple comparisons test.

* Significantly increased surface roughness compared to noncoated controls $(p<0.05)$.

***Significantly increased surface roughness compared to noncoated controls, $[\mathrm{BUS} / \mathrm{DNA}]_{5}$ and $[\mathrm{BUS} / \mathrm{DNA}]_{5}+\mathrm{SBF}$ $(p<0.001)$. fication $(7500 \times)$, however, a uniform surface layer was observed on the implant surface. Immersion in SBF for 2 weeks resulted in granular depositions of different sizes (ranging from $\sim 1-3 \mu \mathrm{m}$ ) over the entire surface of the $[\mathrm{BUS} / \mathrm{DNA}]_{5}+$ SBF-coated implants. High magnification SEM images revealed that each granule consisted of a large number of tiny flake-like crystals. SEM observations of the magnetron sputter-coated CaP implants showed a continuous surface coverage with a rough appearance compared to the other surface modifications.

\section{Implant retrieval}

All 80 rats remained in good health during the experimental period without any postoperative wound healing complications. At sacrifice, no signs of inflammation or adverse tissue reaction could be seen around the implants. Table II depicts the number of implants placed, retrieved after implantation, and included in the histological and histomorphometrical analyses. Of the 80 installed implants, a total of 79 implants could be retrieved. One implant ([BUS/DNA $\left.]_{5}+\mathrm{SBF}\right)$ was not found during retrieval.

\section{Descriptive histological evaluation}

After an implantation period of 1 week, light microscopic examination of the methylene blue/ basic fuchsin-stained sections of the implants and their surrounding tissue demonstrated variable amounts of new bone formation between implants from different experimental groups (Fig. 3). In general, little or no inflammatory cells, such as macrophages and foreign body giant cells were observed and only occasionally an intervening fibrous tissue layer was present between the bone and the implant. In most sections, the drilling procedure appeared to have been accurate. In addition, damage caused by the drilling procedure was only limited, evidenced by the absence of drilling debris and/or fractured bone chips. In 1 implant (CaP), the remains of an hemorrhage were present. Several implants showed the presence of bone marrow or growth plate at the original defect site limiting the amount of bone surrounding the implant. Furthermore, the diameter of the implant bed was occasionally oversized in relation to the implant diameter, resulting in little or no bone-to-implant contact. In all other implants, a close bone-toimplant contact was observed.

After 4 weeks of implantation, the histological sections generally demonstrated an increase in new bone formation. Similarly to week 1 , little or no 


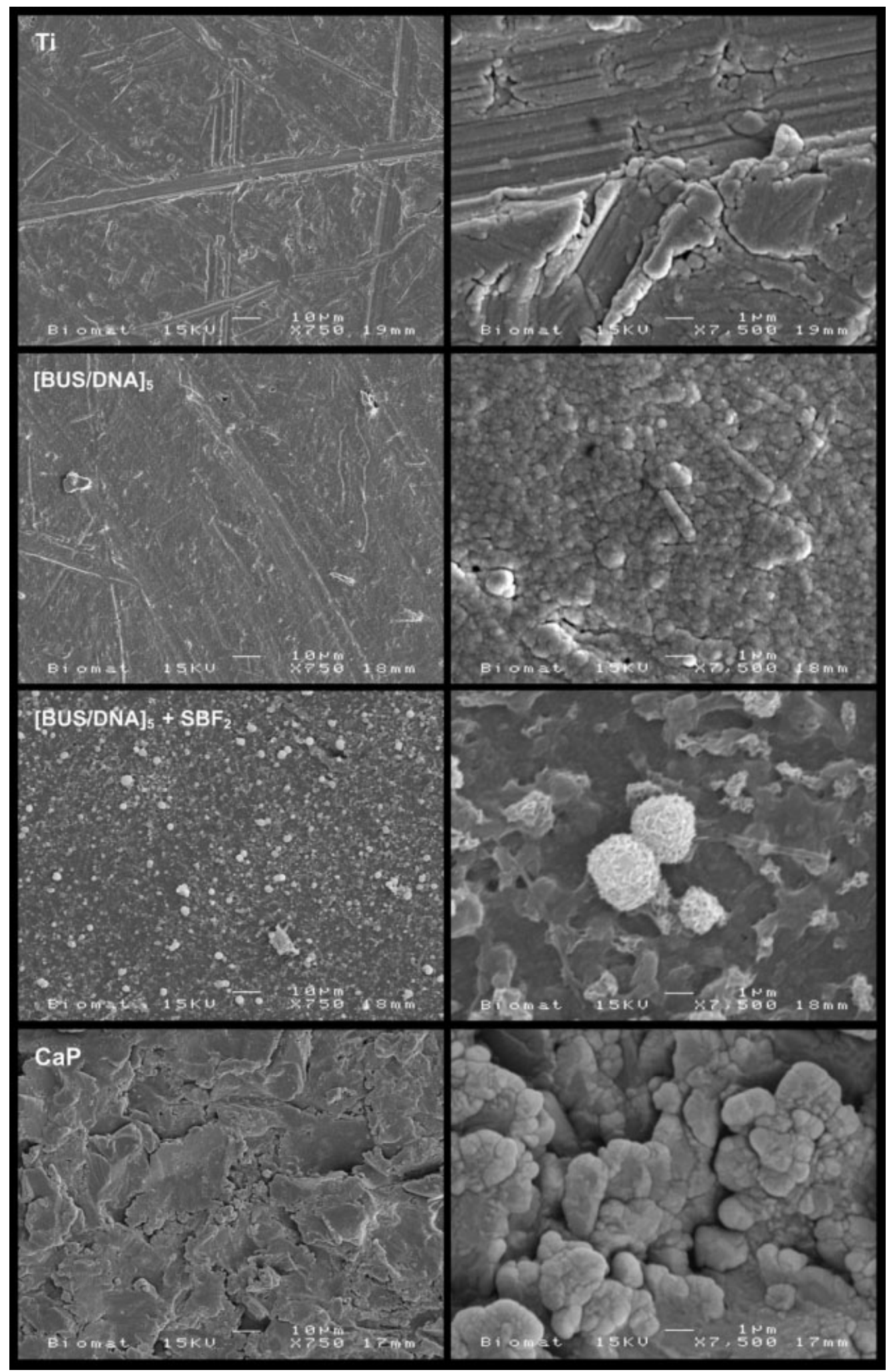

Figure 2. Scanning electron micrographs of cylindrical Ti implants with different surface modifications before implantation. Ti, noncoated control, [BUS/DNA $]_{5},[\mathrm{BUS} / \mathrm{DNA}]_{5}+\mathrm{SBF}$, and CaP. Note the flake-like crystals at the surface of the $[\mathrm{BUS} / \mathrm{DNA}]_{5}+$ SBF-coated implants at the high magnification image.

inflammatory cells were observed. Additionally, in several sections bone marrow or growth plate was present and again in a few sections the diameter of the implant bed was oversized in relation to the implant diameter. In all other implants a close boneto-implant contact was observed. 
TABLE II

Number of Implants Placed, Retrieved, and Used for Histological and Histomorphometrical Analyses

\begin{tabular}{|c|c|c|c|c|c|c|c|c|}
\hline & \multirow{2}{*}{\multicolumn{2}{|c|}{$\begin{array}{c}\text { No. of } \\
\text { Implants Placed }\end{array}$}} & \multirow{2}{*}{\multicolumn{2}{|c|}{$\begin{array}{c}\text { No. of } \\
\text { Implants Retrieved }\end{array}$}} & \multicolumn{4}{|c|}{$\begin{array}{l}\text { No. of Implants Used for } \\
\text { Histomorphometrical Analysis }\end{array}$} \\
\hline & & & & & \multicolumn{2}{|c|}{ BIC } & \multicolumn{2}{|c|}{ BV } \\
\hline & Week 1 & Week 4 & Week 1 & Week 4 & Week 1 & Week 4 & Week 1 & Week 4 \\
\hline Noncoated & 10 & 10 & 10 & 10 & 6 & 8 & 6 & 8 \\
\hline$[\mathrm{BUS} / \mathrm{DNA}]_{5}$ & 10 & 10 & 10 & 10 & 7 & 8 & 7 & 6 \\
\hline$[\mathrm{BUS} / \mathrm{DNA}]_{5}+\mathrm{SBF}$ & 10 & 10 & 10 & $9^{a}$ & 8 & 7 & 8 & 8 \\
\hline $\mathrm{CaP}$ & 10 & 10 & 10 & 10 & 6 & 6 & 5 & 5 \\
\hline
\end{tabular}

${ }^{\mathrm{a}}$ One $[\mathrm{BUS} / \mathrm{DNA}]_{5}+\mathrm{SBF}$ implant was lost after retrieval.

\section{Histomorphometrical analysis}

The number of implants used for histomorphometrical analyses is depicted in Table II. Several implants were excluded for histomorphometrical analyses for different reasons: the presence of bone marrow or growth plate at the defect site, or an oversized implant bed.

Bone-to-implant contact

The results of the bone-to-implant contact measurements and the outcome of the statistical analyses are depicted in Table III. A total of 56 implants were used for bone-to-implant contact measurements. The data illustrate that after an implantation period of 1 week, the noncoated controls showed the statistically significant lowest bone-to-implant contact $(13.1 \% \pm 2.4 \%)$, whereas $[\mathrm{BUS} / \mathrm{DNA}]_{5},[\mathrm{BUS} / \mathrm{DNA}]_{5}+\mathrm{SBF}$ and $\mathrm{CaP}-$ coated implants showed similar bone-to-implant contact $(21.3 \% \pm 6.8 \%, 24.5 \% \pm 5.3 \%$, and $23.5 \% \pm 5.0 \%$, respectively). After an implantation period of 4 weeks, statistically higher bone-to-implant contact values were found for both $[\mathrm{BUS} / \mathrm{DNA}]_{5}+\mathrm{SBF}$ and CaPcoated implants $(41.2 \% \pm 13.0 \%$, and $49.6 \% \pm 13.3 \%)$ compared to noncoated controls as well as [BUS/ DNA $]_{5}$-coated $(23.8 \% \pm 8.3 \%, 21.8 \% \pm 3.2 \%)$ implants. Additionally, statistical comparisons between week 1 and week 4 showed significantly increased bone-to implant contact values for noncoated controls, [BUS/ DNA $]_{5}+$ SBF and CaP-coated implants compared to 1 week, whereas bone-to-implant contact for the $[\mathrm{BUS} / \mathrm{DNA}]_{5}$ group remained constant.

Bone volume

For the bone volume measurements, a total of 53 implants were used, of which the results and statisti-

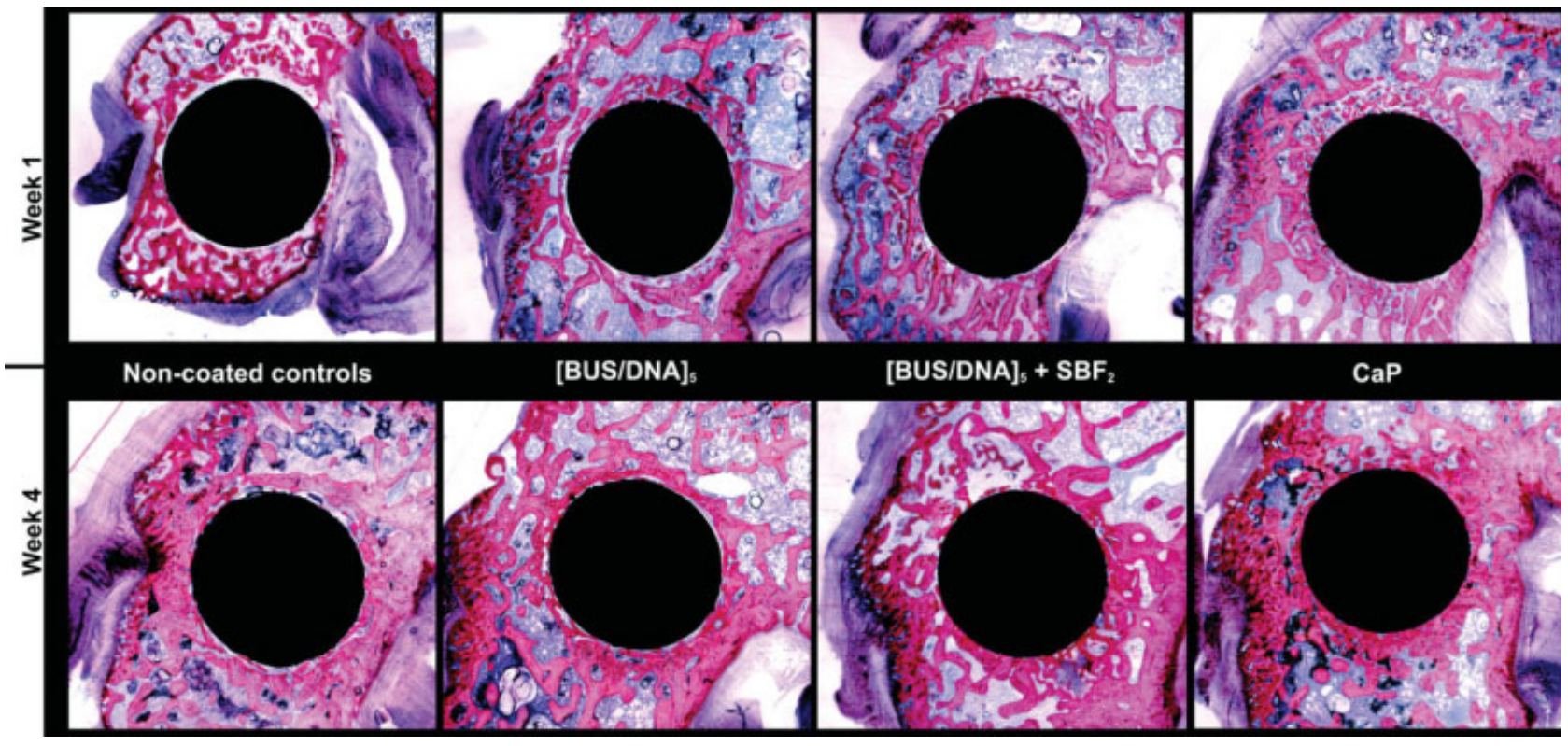

Figure 3. Representative histological sections of cylindrical implants surrounded by bone after 1 and 4 weeks of implantation in the femoral condyles of rats. $1-4$ weeks: noncoated controls; $1-4$ weeks: [BUS/DNA] $]_{5} ; 1-4$ weeks: $[B U S / D N A]_{5}+$ SBF; 1-4 weeks: CaP. [Color figure can be viewed in the online issue, which is available at www.interscience.wiley.com.] 
TABLE III

Bone-Implant Contact (\%) and Bone Volume (\%) (Mean \pm SD)

\begin{tabular}{|c|c|c|c|c|}
\hline & \multicolumn{2}{|c|}{ Bone-Implant Contact (\%) } & \multicolumn{2}{|c|}{ Bone Volume (\%) } \\
\hline & Week 1 & Week 4 & Week 1 & Week 4 \\
\hline Noncoated & $13.1 \pm 2.4$ & $23.8 \pm 8.3^{\mathrm{f}}$ & $53.7 \pm 4.0$ & $60.5 \pm 10.2$ \\
\hline$[\mathrm{BUS} / \mathrm{DNA}]_{5}$ & $21.3 \pm 6.8^{\mathrm{a}}$ & $21.8 \pm 3.2$ & $57.8 \pm 4.0$ & $63.4 \pm 6.8$ \\
\hline$[\mathrm{BUS} / \mathrm{DNA}]_{5}+\mathrm{SBF}$ & $24.5 \pm 5.3^{\mathrm{b}}$ & $41.2 \pm 13.0^{\mathrm{a}, \mathrm{d}, \mathrm{f}}$ & $59.0 \pm 3.7$ & $61.4 \pm 12.0$ \\
\hline $\mathrm{CaP}$ & $23.5 \pm 5.0^{\mathrm{a}}$ & $49.6 \pm 13.3^{c, e, g}$ & $64.7 \pm 7.1^{\mathrm{b}}$ & $67.6 \pm 9.5$ \\
\hline
\end{tabular}

Statistical analyses within week 1 and 4 were performed using a one-way ANOVA, combined with a post hoc TukeyKramer multiple comparisons test. Between week 1 and 4 analyses were performed using an unpaired $t$-test.

Significantly different compared to noncoated controls at each implantation period; ${ }^{\mathrm{a}} p<0.05,{ }^{\mathrm{b}} p<0.01,{ }^{\mathrm{c}} p<0.001$.

Significantly different compared to [BUS/DNA $]_{5}$ at each implantation period; ${ }^{\mathrm{d}} p<0.01,{ }^{\mathrm{e}} p<0.001$.

Significant difference within experimental group between week 1 and 4 ; ${ }^{\mathrm{f}} p<0.05,{ }^{\mathrm{g}} p<0.01$.

cal outcomes are depicted in Table III. The amount of bone volume was determined in a zone of 0.50 $\mathrm{mm}[2.25 \mathrm{~mm}$ (ROI) $-1.75 \mathrm{~mm}$ (implant ø)]. The results showed that after 1 week the amount of bone volume was significantly higher for CaP-coated implants compared to noncoated controls $(64.7 \% \pm$ $7.1 \%)$. After 4 weeks the percentage of bone volume ranged from 60.5 to $67.6 \%$. Statistical testing did not show any significant differences between the individual experimental implant groups for week 4 .

\section{DISCUSSION}

This study was initiated to evaluate the potential in vivo bioactivity of DNA-based coatings, either or not pre-treated in SBF, in a rat femoral condyle model. Noncoated titanium implants and $\mathrm{CaP}$ sputter-coated titanium implants served as negative and positive controls, respectively. After implantation periods of 1 and 4 weeks, the bone-to-implant contact and amount of bone volume were determined histomorphometrically. The results of this study showed that DNA-based coatings, either or not pretreated in SBF, and CaP coatings increased the boneto-implant contact after 1 week compared to noncoated controls. Four weeks of implantation further increased the bone-to-implant contact for noncoated controls, SBF pre-treated DNA-coatings, and CaP coatings, whereas no additional increase in bone-toimplant contact was observed for the DNA-coated implants. Bone volume measurements did not show any significant differences between the individual experimental implant groups at both 1 and 4 weeks postimplantation.

Previous studies by van den Beucken et al. demonstrated the feasibility of the use of multilayered DNA-based coatings for biomaterial purposes, using poly-D-lysine (PDL) and poly(allylamine hydrochloride) $(\mathrm{PAH})$ as cationic components. ${ }^{11}$ Chemical char- acterization of these [PDL/DNA] and [PAH/DNA] films, using XPS and contact angle measurements, showed that the layers in the multilayered coating are not completely separated, but can be regarded as partly mixed. ${ }^{11}$ Several authors stated that the mixing process is a consequence of diffusion of the polyelectrolytes "in" and "out" of the film during build up of the multilayered coating, and has some important limitations. ${ }^{21,22}$ In view of the current study, the major limitation of polyelectrolyte diffusion is the presentation of DNA at the surface of the coating. Because of the diffusion and mixing process, the amount of DNA in the DNA-terminated layer decreases. Consequently, the beneficial properties of DNA as a functional biomaterial, that is, an optimal availability of the phosphate groups at the implant surface, cannot be fully exploited. Additionally, in the absence of discrete layers, the process of incorporation of proteins, drugs, or other biologicals in predetermined layers will be hampered. To overcome these problems, physical barriers can be placed between the various components within a single film, to control the interlayer diffusion. ${ }^{23}$ In the present study, Bis-Ureido-Surfactant (BUS) was used to function as a barrier for the formation of a multicompartment coating. This surfactant molecule functions by the formation of strong hydrogen bonds resulting in well-defined highly ordered ribbon-like bilayer aggregates, ${ }^{18}$ ensuring the presence of DNA at the surface. Apart from acting as a stabilizing unit, bis-urea units can also be used as an anchor for functional molecules, such as growth factors. By using a spacer, these functional molecules will be able to penetrate the surface layer of DNA and become exposed on the surface. ${ }^{18}$ Therefore, by generating multilayered [BUS/DNA]-coatings the functional properties of both the anionic DNA molecule and the cationic counterpart, BUS, can be optimally used.

In the present study, histological data demonstrated that titanium implants deposited with multilayered 
[BUS/DNA] coatings and implanted in the femoral condyles of rats, did not show any adverse tissue reactions after 1 and 4 weeks of implantation. These results indicate that [BUS/DNA] coatings can be regarded as histocompatible. This observation corroborates published data of other experiments, in which DNA-coated implants or DNA-based biomaterials did not show any unfavorable tissue responses after subcutaneous implantation in the back of rats. ${ }^{15,24}$

With respect to histomorphometry, the results of this study indicated that the presence of a multilayered [BUS/DNA] coating favored the initial boneimplant contact. After 4 weeks of implantation, however, no additional effect on the peri-implant bone response was observed. The reason for the absence of an additional response in the DNA-coated group remains unclear. In contrast, SBF pre-treated DNAcoatings and $\mathrm{CaP}$ coatings showed both early and a late positive effect on bone response compared to noncoated controls. It can be hypothesized that this observation might be partly due to the differences in surface roughness between the individual experimental groups. Numerous studies demonstrated effects of surface roughness on the peri-implant bone response $\mathrm{e}^{25-31}$ and in vitro studies have shown that on microrough surfaces, osteoblasts create a microenvironment favorable for new bone formation via a decrease in osteoblast proliferation, and an increase in differentiation and secretion of osteogenesis promoting factors (such as TGF- $\beta 1$ ). ${ }^{30,31}$ A systematic review on animal studies by Shalabi et al., investigating the effects of implant surface roughness on bone response and implant fixation after 12 weeks of implantation, provided evidence for a positive relationship between bone-to-implant contact and surface roughness. ${ }^{32}$ In the present study, the positive controls, that is, the CaP-coated implants, had a significantly increased roughness due to the necessity of grit-blasting prior to $\mathrm{CaP}$ coating deposition through $\mathrm{RF}$ magnetron sputtering for coating adhesive reasons. However, it needs to be emphasized that this experimental group, which has demonstrated superior bone responses in previous animal experiments, ${ }^{33,34}$ served as positive control. To maximally diminish potential effects of differences in roughness on bone responses, the remaining three experimental groups (noncoated controls, [BUS/DNA] and [BUS/DNA] + SBF) received no conventional treatment to roughen the surface. Regarding the relationship between bone-to-implant contact and surface roughness, as described by Shalabi et al., a positive correlation was found for SBF pre-treated DNA-coated implants and CaP-coated implants. Both groups showed a statistically higher surface roughness and increased bone-to-implant contact compared to noncoated controls. The DNAcoated implants did not show a positive correlation, though SBF pre-treated implants were only slightly, but not significantly rougher. Therefore, it is not likely that the increased osteogenic response to SBF pretreated DNA-coatings is solely due to variations in surface roughness. ${ }^{26}$ It can be further hypothesized that this observation might be due to the presence of $\mathrm{CaP}$ depositions on the DNA-coated implant surfaces after immersion in SBF (Fig. 2). After all, the presence of a biologically active bone-like apatite layer on an implant surface enhances the formation of a tight chemical bond between the bone apatite and surface apatite, favoring the osteogenic response. ${ }^{4,35}$

Beside focusing on the importance of altering implant surfaces to improve implant stability and bone healing, another essential feature that needs attention is the surgical implant procedure in relation to the animal implantation model. Although the rat femoral condyle model is easy to perform, requires little operation time and most important, has a low inconvenience score for the animals, still some important limitations are related to this model. Histological evaluation showed that in several sections the implant diameter resembled the mediolateral diameter of the lateral condyle, resulting in little or no bone tissue surrounding the implant. Because of the limited dimension of the lateral condyle, implants were placed in, or in contact with, the growth plate or bone marrow cavity. In addition, with respect to the small implant diameter, the defect was easily drilled slightly oversized in relation to the implant diameter, resulting in little or no bone-to-implant contact, or the presence of an intervening fibrous tissue layer. To overcome these problems, a suggestion would be to decrease the implant diameter, to switch to a bigger animal model, or to place the implants in a different implantation location, such as the intramedullary cavity ${ }^{36}$ or different implant orientation, that is, from medial to lateral ${ }^{37}$ (instead of from distal to proximal as performed in the present study).

In summary, this study demonstrates that DNAbased coatings are histocompatible and favor the early bone response. SBF-pretreated DNA-based coatings were found to increase both the early and the late peri-implant bone response.

The authors acknowledge Nichiro Corporation (Kawasaki-city, Japan) for providing DNA, and the Laboratory for Macromolecular and Organic Chemistry (University of Technology, Eindhoven, The Netherlands) for providing BUS. Ms. Natasja van Dijk (Department of Periodontology and Biomaterials, Radboud University Nijmegen Medical Center, The Netherlands) is acknowledged for her help with the histological preparations and histomorphometrical analysis. Dr. E.M. Bronkhorst (Department of Preventive and Curative Dentistry, Radboud University Nijmegen Medical Center, The Netherlands) is acknowledged for his assistance on the statistical analysis. 


\section{References}

1. Galante JO, Lemons J, Spector M, Wilson PD Jr., Wright TM. The biologic effects of implant materials. J Orthop Res 1991;9: 760-775.

2. Jansen JA, Wolke JG, Swann S, Van der Waerden JP, de Groot K. Application of magnetron sputtering for producing ceramic coatings on implant materials. Clin Oral Implants Res 1993;4:28-34.

3. Leeuwenburgh SC, Wolke JG, Lommen L, Pooters T, Schoonman J, Jansen JA. Mechanical properties of porous, electrosprayed calcium phosphate coatings. J Biomed Mater Res A 2006;78:558-569.

4. Ducheyne P, Bianco P, Radin S, Schepers E. Bioactive materials: Mechanisms and bioengineering considerations. In: Ducheyne $\mathrm{P}$, Kokubo T, van Blitterswijk CA, editors. Bone-Bonding Biomaterials. Leiderdorp, The Netherlands: Reed Healthcare Communications; 1992. p 1-12.

5. Hulshoff JE, van Dijk K, van der Waerden JP, Wolke JG, Kalk W, Jansen JA. Evaluation of plasma-spray and magnetron-sputter Ca-P-coated implants: an in vivo experiment using rabbits. J Biomed Mater Res 1996;31:329337.

6. Sun L, Berndt CC, Gross KA, Kucuk A. Material fundamentals and clinical performance of plasma-sprayed hydroxyapatite coatings: A review. J Biomed Mater Res 2001;58:570592.

7. Hulshoff JE, van Dijk K, van der Waerden JP, Wolke JG, Kalk W, Jansen JA. Engineering craniofacial scaffolds. Orthod Craniofac Res 2005;8:162-173.

8. Kokubo T, Takadama H. How useful is SBF in predicting in vivo bone bioactivity? Biomaterials 2006;27:2907-2915.

9. Liu Q, Ding J, Mante FK, Wunder SL, Baran GR. The role of surface functional groups in calcium phosphate nucleation on titanium foil: A self-assembled monolayer technique. Biomaterials 2002;23:3103-3111.

10. van den Beucken JJ, Walboomers XF, Leeuwenburgh SC, Vos MR, Sommerdijk NA, Nolte RJ, Jansen JA. Multilayered DNA coatings: In vitro bioactivity studies and effects on osteoblastlike cell behavior. Acta Biomater 2007;3:587-596.

11. van den Beucken JJ, Vos MR, Thune PC, Hayakawa T, Fukushima T, Okahata Y, Walboomers XF, Sommerdijk NA, Nolte RJ, Jansen JA. Fabrication, characterization, and biological assessment of multilayered DNA-coatings for biomaterial purposes. Biomaterials 2006;27:691-701.

12. Etienne O, Picart C, Taddei C, Keller P, Hubsch E, Schaaf P, Voegel JC, Haikel Y, Ogier JA, Egles C. Polyelectrolyte multilayer film coating and stability at the surfaces of oral prosthesis base polymers: An in vitro and in vivo study. J Dent Res 2006;85:44-48.

13. Etienne O, Gasnier C, Taddei C, Voegel JC, Aunis D, Schaaf $\mathrm{P}$, Metz-Boutigue $\mathrm{MH}$, Bolcato-Bellemin AL, Egles C. Antifungal coating by biofunctionalized polyelectrolyte multilayered films. Biomaterials 2005;26:6704-6712.

14. Schultz P, Vautier D, Richert L, Jessel N, Haikel Y, Schaaf P, Voegel JC, Ogier J, Debry C. Polyelectrolyte multilayers functionalized by a synthetic analogue of an anti-inflammatory peptide, alpha-MSH, for coating a tracheal prosthesis. Biomaterials 2005;26:2621-2630.

15. van den Beucken JJ, Walboomers XF, Vos MR, Sommerdijk NA, Nolte RJ, Jansen JA. Cyto- and histocompatibility of multilayered DNA-coatings on titanium. J Biomed Mater Res A 2006;77:202-211.

16. van den Beucken JJ, Walboomers XF, Boerman OC, Vos MR, Sommerdijk NA, Hayakawa T, Fukushima T, Okahata Y, Nolte RJ, Jansen JA. Functionalization of multilayered DNAcoatings with bone morphogenetic protein 2. J Control Release 2006;113:63-72.
17. van den Beucken JJ, Walboomers XF, Nillesen ST, Vos MR, Sommerdijk NA, van Kuppevelt TH, Nolte RJ, Jansen JA. In vitro and in vivo effects of deoxyribonucleic acid-based coatings funtionalized with vascular endothelial growth factor. Tissue Eng 2007;13:711-720.

18. Vos MR, Jardl GE, Pallas AL, Breurken M, van Asselen OLJ, Bomans PHH, Leclere PELG, Frederik PM, Nolte RJM, Sommerdijk NAJM. The bis-urea motif as a tool to functionalize self-assembled nanoribbons. J Am Chem Soc 2005;127:1676816769.

19. Wolke JG, van Dijk K, Schaeken HG, de Groot K, Jansen JA. Study of the surface characteristics of magnetron-sputter calcium phosphate coatings. J Biomed Mater Res 1994;28:14771484.

20. van der Lubbe HB, Klein $\mathrm{CP}$, de Groot K. A simple method for preparing thin (10 microM) histological sections of undecalcified plastic embedded bone with implants. Stain Technol 1988;63:171-176.

21. Garza JM, Schaaf P, Muller S, Ball V, Stoltz JF, Voegel JC, Lavalle P. Multicompartment films made of alternate polyelectrolyte multilayers of exponential and linear growth. Langmuir 2004;20:7298-7302.

22. Picart C, Mutterer J, Richert L, Luo Y, Prestwich GD, Schaaf P, Voegel JC, Lavalle P. Molecular basis for the explanation of the exponential growth of polyelectrolyte multilayers. Proc Natl Acad Sci USA 2002;99:12531-12535.

23. Wood KC, Chuang HF, Batten RD, Lynn DM, Hammond PT. Controlling interlayer diffusion to achieve sustained, multiagent delivery from layer-by-layer thin films. Proc Natl Acad Sci USA 2006;103:10207-10212.

24. Fukushima T, Inoue Y, Hayakawa T, Taniguchi K, Miyazaki K, Okahata Y. Preparation of and tissue response to DNA-lipid films. J Dent Res 2001;80:1772-1776.

25. Abrahamsson I, Berglundh T, Linder E, Lang NP, Lindhe J. Early bone formation adjacent to rough and turned endosseous implant surfaces. An experimental study in the dog. Clin Oral Implants Res 2004;15:381-392.

26. Svehla M, Morberg P, Zicat B, Bruce W, Sonnabend D, Walsh WR. Morphometric and mechanical evaluation of titanium implant integration: comparison of five surface structures. J Biomed Mater Res 2000;51:15-22.

27. Grizon F, Aguado E, Hure G, Basle MF, Chappard D. Enhanced bone integration of implants with increased surface roughness: A long term study in the sheep. J Dent 2002;30: 195-203.

28. Cochran DL, Schenk RK, Lussi A, Higginbottom FL, Buser D. Bone response to unloaded and loaded titanium implants with a sandblasted and acid-etched surface: A histometric study in the canine mandible. J Biomed Mater Res 1998;40: $1-11$.

29. Wennerberg A, Albrektsson T, Andersson B, Krol JJ. A histomorphometric and removal torque study of screw-shaped titanium implants with three different surface topographies. Clin Oral Implants Res 1995;6:24-30.

30. Boyan BD, Lossdorfer S, Wang L, Zhao G, Lohmann CH, Cochran DL, Schwartz Z. Osteoblasts generate an osteogenic microenvironment when grown on surfaces with rough microtopographies. Eur Cell Mater 2003;6:22-27.

31. Lossdorfer S, Schwartz Z, Wang L, Lohmann CH, Turner JD, Wieland M, Cochran DL, Boyan BD. Microrough implant surface topographies increase osteogenesis by reducing osteoclast formation and activity. J Biomed Mater Res A 2004;70: 361-369.

32. Shalabi MM, Gortemaker A, Van't Hof MA, Jansen JA, Creugers NH. Implant surface roughness and bone healing: A systematic review. J Dent Res 2006;85:496-500.

33. Vercaigne S, Wolke JG, Naert I, Jansen JA. A histological evaluation of $\mathrm{TiO} 2$-gritblasted and $\mathrm{Ca}-\mathrm{P}$ magnetron sputter 
coated implants placed into the trabecular bone of the goat: Part 2. Clin Oral Implants Res 2000;11:314-324.

34. Hayakawa T, Yoshinari M, Nemoto K, Wolke JG, Jansen JA. Effect of surface roughness and calcium phosphate coating on the implant/bone response. Clin Oral Implants Res 2000; 11:296-304.

35. Puleo DA, Nanci A. Understanding and controlling the boneimplant interface. Biomaterials 1999;20:2311-2321.
36. Kujala S, Tuukkanen J, Jamsa T, Danilov A, Pramila A, Ryhanen J. Comparison of the bone modeling effects caused by curved and straight nickel-titanium intramedullary nails. J Mater Sci Mater Med 2002;13:1157-1161.

37. Fujibayashi S, Neo M, Kim HM, Kokubo T, Nakamura T. A comparative study between in vivo bone ingrowth and in vitro apatite formation on $\mathrm{Na} 2 \mathrm{O}-\mathrm{CaO}-\mathrm{SiO} 2$ glasses. Biomaterials 2003;24:1349-1356. 